\title{
Bullying in the Classroom
}

\author{
Jon A Shaw* \\ Professor of Clinical, Psychiatry and Behavioral Sciences, USA \\ Received: 眥 May 18, 2018; Published: 眥 May 25, 2018 \\ *Corresponding author: Jon A Shaw, MD, MS, Professor of Clinical, Psychiatry and Behavioral Sciences, USA
}

\begin{abstract}
Over the last decade, we have seen a dramatic increase in violent acts perpetrated by youth (Dahlberg, 1998). The school shootings have awakened the public, the media, community, and mental health professionals to the endemic nature of violence in our school population. Violence is defined as physically assaultive behavior. Aggravated assaults by males less than 18 years of age increased by $88 \%$ from 1985-1994 while aggravated assaults by females increased by $134 \%$ in the same time period (Dahlberg, 1998). A number of studies have documented that a child who is aggressive in his preschool and early elementary school years is at high risk for being a delinquent during his adolescent years.
\end{abstract}

\section{Introduction}

A child who is a bully during elementary school not only terrorizes his peers, but also is at a very high risk of becoming a delinquent, gang member, or even a criminal in adulthood [1,2]. Olweus (1992) found that if a child is a bully in the sixth grade he has a $60 \%$ chance of having a criminal conviction by the age of 24 years. Bullying behavior among students is a universal problem present in every school population. Bullying is defined as the intentional, repeated production of physical and/or psychological injury or discomfort upon another person who usually is unable to defend him/herself [3,4]. Bullying may take the form of any number of aggressive and antisocial behaviors such as insulting, teasing, threatening, verbal and physical abusive behaviors, social exclusion, alienation, or rumor mongering [5,6]. Bullying behaviors may be perpetrated either by boys or girls, or individuals or groups, but it always involves an imbalance of power [6]. A nation-wide study in Norway found that approximately $15 \%$ of children are involved in bullying behavior. Nine percent were bullies and $7 \%$ were the victims of bullies. Approximately 2-3\% participated in both being the victims of bullies and also being bullies [4]. A survey in the United States revealed that $30 \%$ of sixth through tenth-grade students was involved in bullying behavior [3].

Bullies are usually ready to utilize aggression to resolve conflict and to solve interpersonal problems [7]. They tend to be stronger than others and have little empathy for their victims. The victims are children who are usually described as anxious, sensitive, insecure, and weaker [4]. Olweus [7,8] carried out a twoyear intervention program throughout Norway and was able to reduce the incidence of bullying behavior by 50\%. A program for bully proofing an elementary school was developed by a group of mental health professionals [9]. This program focuses on a schoolwide intervention with the intent of changing the atmosphere of the school through staff training, student instruction, support of the victims, intervention with bullies, development of the caring majority, and working with parents. A later version was developed for a middle school population [6]. We implemented this bully proofing program in an elementary school of over 1000 students. Our pilot project was designed to collect data on fourth and sixth graders to determine if this program could improve antisocial and problematic behaviors.

\section{Methods}

\section{Subjects}

Fourth and sixth grade children from an elementary school in metropolitan South Florida participated in the study $(\mathrm{N}=226)$. This school is centrally located in a culturally diverse neighborhood and our sample is representative of the South Florida community. This sample comprised of $52 \%(n=118)$ being in the fourth grade and $48 \%(n=108)$ being in the sixth grade with a mean age of 10.4 $(\mathrm{SD}=1.1, \mathrm{R}=8,13)$. The ages of the fourth graders ranged from 8 to 11 years, with a mean age of 9.5 years ( $S D=0.6)$, and included 49 females and 69 males. Sixth graders included 51 females and 57 males with a mean age of 11.4 years ( $S D=1.1, \mathrm{R}=10,13)$. The ethnic distribution of the fourth graders was: 18 white, non-Hispanics, 9 black, non-hispanics, 89 hispanics, and 2 of other or multiracial origin. The ethnic distribution of the sixth graders was: 17 white, 
non-hispanics, 7 black, non-hispanics, 83 hispanics, and 1 of other or multiracial origin.

\section{The Bully Proofing Intervention}

We utilized the bully proofing psycho educational intervention module developed for elementary schools by Garrity et al. [9]. This program consists of five components: staff training, student instruction, support of victims, intervention with bullies, and collaboration with parents of bullies and victims. The primary focus of the program is to develop a comprehensive system for identifying and interrupting bullying behaviors by including every person at the school in the educational-intervention program, including staff, teachers, and students.

The initial intervention included a day long workshop with all fourth and sixth grade teachers and staff. They were shown how to bully proof their school, taught how to identify bullies and victims, and instructed in intervention strategies and the dynamics and risks of bullying behavior. A second half-day workshop was held for parents to inform them of the nature of the program, the importance of disrupting bullying behavior, and their role in supporting the bully proofing program of the school. Finally, a social worker met with teachers and they planned out the specific classroom objectives entailed in the six-session program for each class focusing on friendship, bullies, and conflict resolution strategies. Approximately 6 months later, another session was held with the teachers to review the components of the bully proofing program. Strengths and weaknesses of the program were reviewed and they were instructed again on the process of identifying bullies, victims, and bullying behaviors.

\section{Measure}

At the beginning of the academic year, all fourth and sixth grade teachers were given a modified version of the Conners' Rating Scales (CRS; Conners, 1989). We modified the CRS to only include the profiles for conduct disorder, anxious/shy, restless/disorganized, antisocial, hyperactive/immature, and the hyperactivity index. The CRS is a popular scale used to characterize numerous behavior patterns in children. At the follow-up session 6 months later, the teachers were asked to complete the CRS again. The teachers were paid $\$ 50$ for their participation in the study.

\section{Data Analysis}

Data were analyzed using the Statistical Package for the Social Sciences software. Frequency and descriptive statistics were calculated to check all relevant characteristics of the data. The primary independent variable, classification status of the student, e.g., student was labeled as a bully, victim, or neither, was tested with either the Student's t-test or within the general linear model repeated-measures ANOVA framework to detect differences in the scales on the CRS. The Bonferroni correction was used for multiple comparisons to determine differences between groups. For demographic, categorical variables, Pearson's Chi-Square was employed to determine any significant differences in proportions.

\section{Results}

\section{Classification Status}

We used the response on the CRS at pre-intervention to categorize the student as: neither bully nor victim (NBV; $n=139$ ), bully (BU; $n=45$ ), victim (VI; $n=34$ ), or bully/victim (BV; $n=8)$. They were labeled as a BU based on the teacher's response to the CRS item, "Bullying," and were categorized as a VI for the item response to, "Lets him/herself get pushed around by other children." Children were classified as BV based on the responses to both items. This classification was used as the independent variable for subsequent analyses to determine differences on the CRS scales. Chi-square analysis found no significant differences for the classification variable with grade and gender. A one-way ANOVA found no significant difference for the classification variable with age.

\section{BU, VI, and BV at Pre-Intervention}

A one-way ANOVA was employed to analyze differences among BU, VI, and BV at time one for each of the six scales on the CRS (Figure 1). For conduct disorder, a significant difference was found between groups $(\mathrm{F}=15.7(2,84), \mathrm{p}<.001)$, and pair wise comparisons revealed that VI scored significantly less than BU and BV. A significant difference was found between groups for anxious/shy $(\mathrm{F}=9.3(2,84), \mathrm{p}<.001)$, and post-hoc tests revealed that BU scored significantly lower than BV and VI. For restless/ disorganized $(\mathrm{F}=6.1(2,84), \mathrm{p}<.01)$, antisocial $(\mathrm{F}=7.0(2,84)$, $\mathrm{p}<.01)$, and hyperactivity index $(\mathrm{F}=8.5(2,84), \mathrm{p}<.001)$, significant differences were found between groups and pair wise comparisons determined that BU scored significantly higher than VI on each scale. On the hyperactive/immature scale, a significant difference was found between groups $(\mathrm{F}=3.5(2,84), \mathrm{p}<.05)$, and post-hoc tests showed that BV scored significantly higher than VI.

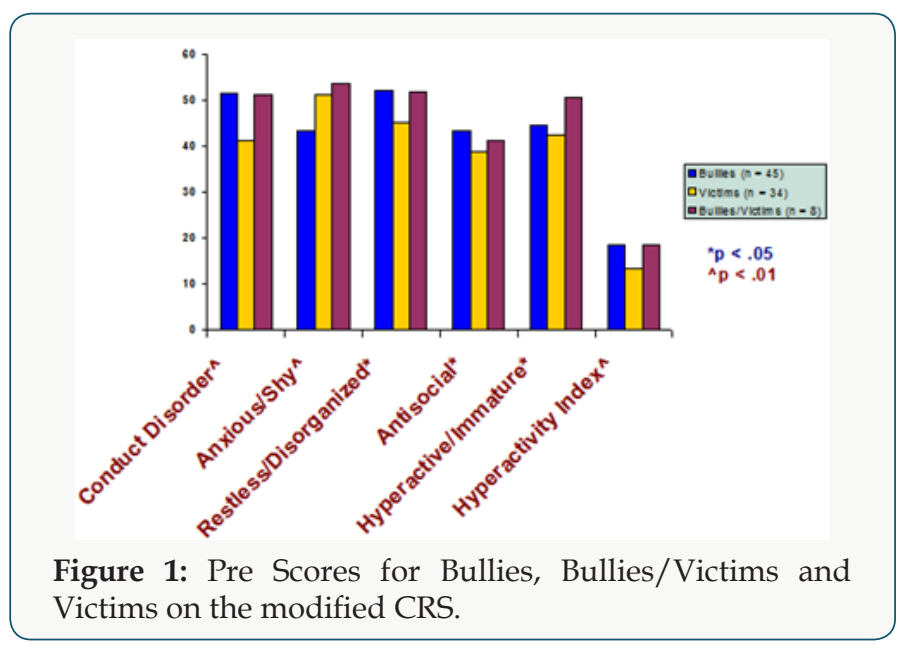

\section{Comparisons between Pre- and Post-Intervention}

For the entire sample, significant differences were found for conduct disorder, anxious/shy, restless/disorganized, hyperactive/ immature, and hyperactivity index. Among BU, conduct disorder, restless/disorganized, hyperactive/immature, and hyperactivity index significantly reduced from pre-intervention to postintervention (Figure 2). Conduct disorder, Anxious/Shy, Restless/ 
Disorganized, Hyperactive/Immature, and Hyperactivity Index significantly changed from Time 1 to Time 2 for the VI (Figure 3). For the BV, conduct disorder, restless/disorganized, hyperactive/ immature, and hyperactivity index was significantly different (Figure 4).
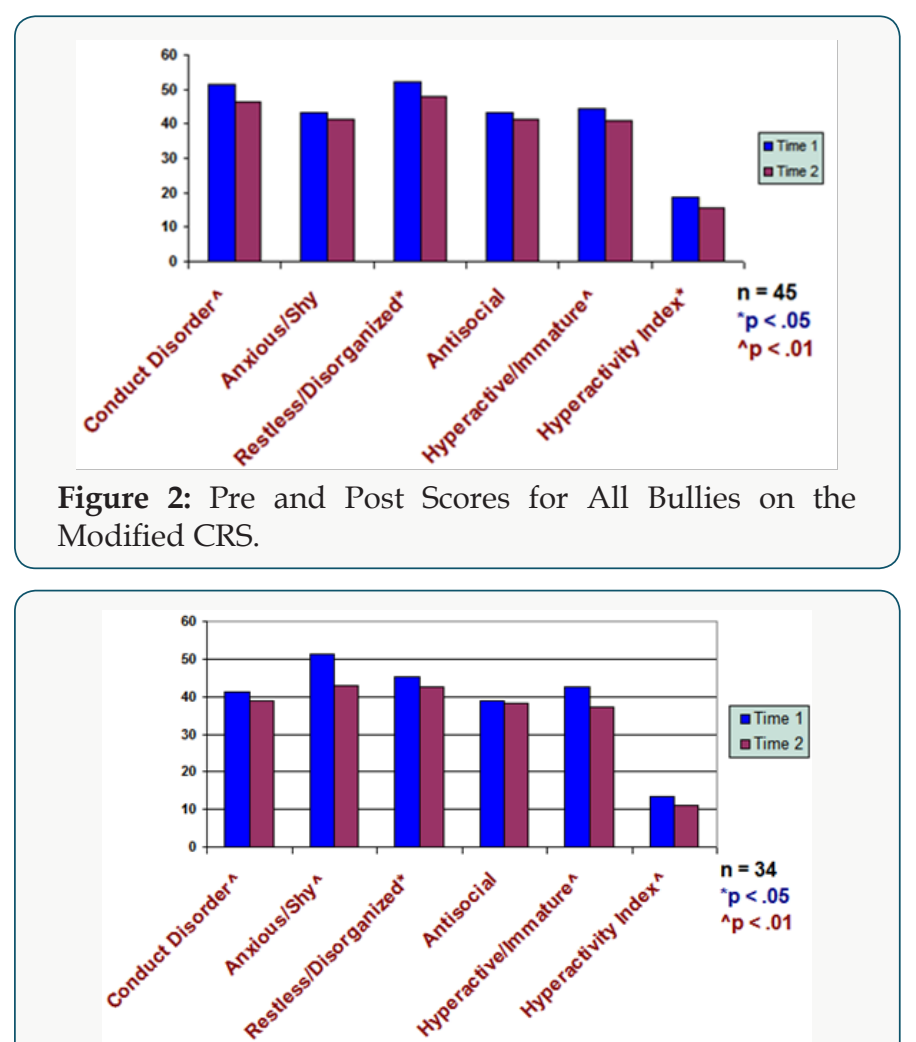

Figure 3: Pre and Post Scores for All Victims on the Modified CRS.

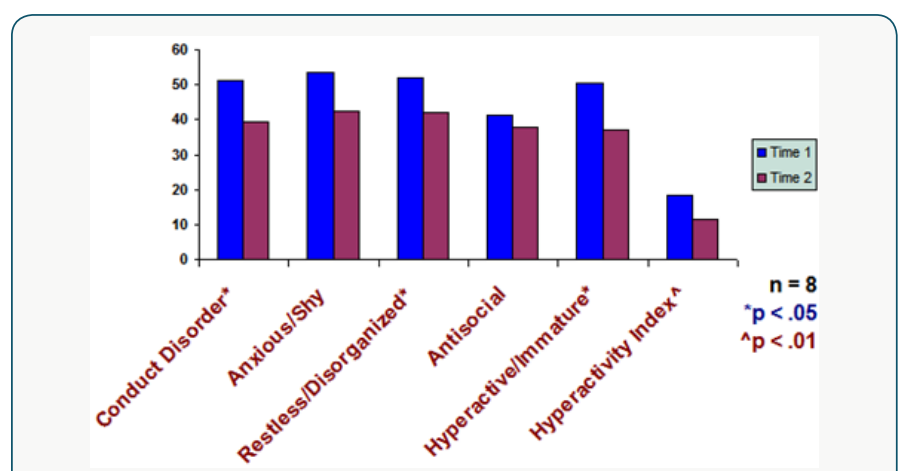

Figure 4: Pre and Post Scores for All Bullies/Victims on the Modified CRS.

\section{Comparisons among NBV, BU, VI, and BV at Pre- and Post-Intervention}

Repeated measures ANOVA were used to analyze differences among NBV, BU, VI, and BV at pre- and post-intervention for each of the six scales on the CRS. For conduct disorder, significant differences were found between groups $(F=43.0(3,222), p<.001)$, within subjects $(F=33.0(1,222), p<.001)$, and the interaction between group status and time $(\mathrm{F}=12.7(3,222), \mathrm{p}<.001)$. Pair wise comparisons revealed that BU scored significantly higher than NBV and VI. BV scored significantly higher than VI and NBV.

Significant differences were found between groups for anxious/shy $(\mathrm{F}=14.7(3,222), \mathrm{p}<.001)$, within subjects $(\mathrm{F}=34.9$ $(1,222), p<.001)$, and the interaction between group status and time $(\mathrm{F}=10.5(3,222), \mathrm{p}<.001)$. Post-hoc tests revealed that $\mathrm{BU}$ scored significantly lower than BV and VI. VI scored significantly higher than NBV, and BV were significantly higher than NBV. For restless/disorganized, [between $(\mathrm{F}=17.5(3,222), \mathrm{p}<.001)$, within $(\mathrm{F}=20.9(1,222), \mathrm{p}<.001)$, and interaction $(\mathrm{F}=6.4(3,222), \mathrm{p}<.001)]$, antisocial [between $(\mathrm{F}=23.8(3,222), \mathrm{p}<.001)$, within $(\mathrm{F}=7.5(1$, 222), $\mathrm{p}<.001)$, and interaction $(\mathrm{F}=4.4(3,222), \mathrm{p}<.001)]$, and hyperactivity index [between $(\mathrm{F}=27.9(3,222), \mathrm{p}<.001)$, within $(\mathrm{F}=32.7(1,222), \mathrm{p}<.001)$, and interaction $(\mathrm{F}=7.3(3,222), \mathrm{p}<.001)]$, significant differences were found and pair wise comparisons determined that BU scored significantly higher than NBV and VI for each scale.

On the hyperactive/immature scale, a significant difference was found between groups $(\mathrm{F}=17.9(3,222), \mathrm{p}<.001)$, within subjects $(\mathrm{F}=56.8(1,222), \mathrm{p}<.001)$, and the interaction between group status and time $(\mathrm{F}=14.3(3,222), \mathrm{p}<.001)$, and post-hoc tests showed that BU scored significantly higher than NBV and VI and VI and BV scored significantly higher than NBV (Table 1).

Table 1: Mean Scores at Time 1 and Time 2 for All Scales on the CRS.

\begin{tabular}{|c|c|c|c|c|c|}
\hline & & $\begin{array}{c}\text { NBV } \\
(n=139) \\
M, S D\end{array}$ & $\begin{array}{c}\text { BU } \\
(n=45) \\
M, S D\end{array}$ & $\begin{array}{c}\text { VI } \\
(n=34) \\
M, S D\end{array}$ & $\begin{array}{c}\text { BV }(n=8) \\
M, S D\end{array}$ \\
\hline \multirow{2}{*}{$\begin{array}{l}\text { Conduct } \\
\text { Disorder }\end{array}$} & $\mathrm{T} 1$ & $\begin{array}{c}39.8 \\
(3.86)\end{array}$ & $\begin{array}{c}51.6 \\
(10.39)\end{array}$ & $\begin{array}{c}41.2 \\
(3.91)\end{array}$ & $\begin{array}{c}51.3 \\
(9.85)\end{array}$ \\
\hline & $\mathrm{T} 2$ & $\begin{array}{c}40.5 \\
(5.54)\end{array}$ & $\begin{array}{c}46.6 \\
(9.23)\end{array}$ & $\begin{array}{c}38.8 \\
(2.79)\end{array}$ & $\begin{array}{c}39.5 \\
(3.12)\end{array}$ \\
\hline \multirow[b]{2}{*}{ Anxious/Shy } & $\mathrm{T} 1$ & $\begin{array}{c}41.9 \\
(5.59)\end{array}$ & $\begin{array}{c}43.4 \\
(7.20)\end{array}$ & $\begin{array}{c}51.2 \\
(9.66)\end{array}$ & $\begin{array}{c}53.6 \\
(14.49)\end{array}$ \\
\hline & $\mathrm{T} 2$ & $\begin{array}{c}41.5 \\
(5.56)\end{array}$ & $\begin{array}{c}41.2 \\
(6.02)\end{array}$ & $\begin{array}{c}42.9 \\
(5.99)\end{array}$ & $\begin{array}{c}42.4 \\
(7.78)\end{array}$ \\
\hline \multirow[b]{2}{*}{$\begin{array}{c}\text { Restless/ } \\
\text { Disorganized }\end{array}$} & $\mathrm{T} 1$ & $\begin{array}{c}43.9 \\
(5.34)\end{array}$ & $\begin{array}{c}52.1 \\
(10.66)\end{array}$ & $\begin{array}{c}45.2 \\
(6.38)\end{array}$ & $\begin{array}{c}51.9 \\
(8.31)\end{array}$ \\
\hline & $\mathrm{T} 2$ & $\begin{array}{c}44.2 \\
(6.16)\end{array}$ & $\begin{array}{c}48.1 \\
(7.79)\end{array}$ & $\begin{array}{c}42.4 \\
(2.84)\end{array}$ & $\begin{array}{c}42.0 \\
(1.93)\end{array}$ \\
\hline \multirow[b]{2}{*}{ Antisocial } & $\mathrm{T} 1$ & $\begin{array}{c}37.9 \\
(2.89)\end{array}$ & $\begin{array}{c}43.2 \\
(5.91)\end{array}$ & $\begin{array}{c}38.9 \\
(3.36)\end{array}$ & $\begin{array}{c}41.1 \\
(6.29)\end{array}$ \\
\hline & $\mathrm{T} 2$ & $\begin{array}{c}38.4 \\
(3.23)\end{array}$ & $\begin{array}{c}41.2 \\
(4.77)\end{array}$ & $\begin{array}{c}38.2 \\
(2.46)\end{array}$ & $\begin{array}{c}37.8 \\
(2.12)\end{array}$ \\
\hline
\end{tabular}




\begin{tabular}{|c|c|c|c|c|c|}
\hline \multirow[b]{2}{*}{$\begin{array}{l}\text { Hyperactive/ } \\
\text { Immature }\end{array}$} & $\mathrm{T} 1$ & $\begin{array}{c}37.6 \\
(4.55)\end{array}$ & $\begin{array}{c}44.5 \\
(8.13)\end{array}$ & $\begin{array}{c}42.5 \\
(6.22)\end{array}$ & $\begin{array}{c}50.5 \\
(11.63)\end{array}$ \\
\hline & $\mathrm{T} 2$ & $\begin{array}{c}37.5 \\
(4.81)\end{array}$ & $\begin{array}{c}40.8 \\
(7.22)\end{array}$ & $\begin{array}{c}37.3 \\
(4.91)\end{array}$ & $\begin{array}{c}37.0 \\
(3.25)\end{array}$ \\
\hline \multirow{2}{*}{$\begin{array}{l}\text { Hyperactivity } \\
\text { Index }\end{array}$} & $\mathrm{T} 1$ & $\begin{array}{c}12.1 \\
(3.25)\end{array}$ & $\begin{array}{c}18.6 \\
(7.09)\end{array}$ & $\begin{array}{c}13.3 \\
(3.77)\end{array}$ & $\begin{array}{c}18.5 \\
(5.01)\end{array}$ \\
\hline & $\mathrm{T} 2$ & $\begin{array}{c}11.8 \\
(3.42)\end{array}$ & $\begin{array}{c}15.6 \\
(6.02)\end{array}$ & $\begin{array}{c}11.2 \\
(2.75)\end{array}$ & $\begin{array}{c}11.6 \\
(1.92)\end{array}$ \\
\hline
\end{tabular}

\section{Comparisons between Male and Female BU}

Similar analyses were performed comparing the scores between males and females who were classified as BU. On the hyperactivity index, males were significantly higher $(\mathrm{F}=4.6(1,43), \mathrm{p}<.05)$. A within-subjects difference was also found $(\mathrm{F}=8.4(1,43), \mathrm{p}<.01)$, but the interaction between status and time was non-significant. A significant interaction between group and time was found for conduct disorder $(\mathrm{F}=4.8(1,43), \mathrm{p}<.05)$, revealing that the score for females changed significantly more than for the males.

\section{Comparisons between Male and Female VI}

We compared the pre- and post- intervention scores between males and females who were classified as VI. No differences were found between groups or for the interaction between status and time.

\section{Comparisons between Fourth and Sixth Grade BU}

Repeated measures were performed comparing the scores between fourth and sixth grade BU. For conduct disorder, fourth graders scored significantly higher than the sixth graders $(\mathrm{F}=3.95$ $(1,43), p=.05)$, and the within subjects $(F=11.0(1,43), p<.01)$ and interaction between group status and time $(\mathrm{F}=9.3(1,43), \mathrm{p}<.01)$ were also significant. A significant interaction between group and time was found for anxious/shy $(F=5.5(1,43), p<.05)$, restlessdisorganized $(\mathrm{F}=5.9(1,43), \mathrm{p}<.05)$, and the hyperactive/immature scale $(F=6.1(1,43), p<.05)$, revealing that the score for sixth graders changed significantly more than for the fourth graders. Fourth graders scored significantly higher on the antisocial scale $(\mathrm{F}=8.1(1,43), \mathrm{p}<.01)$. A within-subjects $(\mathrm{F}=4.4(1,43), \mathrm{p}<.05)$ effect was also found, but the interaction between status and time was non-significant.

Comparisons between Fourth and Sixth Grade VI. Similar repeated measures were performed comparing the scores between fourth and sixth grade VI. For conduct disorder, a significant difference was found between groups $(F=4.81(1,32), p<.05)$, within subjects $(\mathrm{F}=11.2(1,32), \mathrm{p}<.01)$, and the interaction between group status and time $(\mathrm{F}=4.7(1,32), \mathrm{p}<.05)$. A significant interaction between group and time was found for restless-disorganized $(\mathrm{F}=4.2$ $(1,32), p<.05)$, showing that the score for sixth graders changed significantly more than for the fourth graders. The antisocial $(\mathrm{F}=4.1$ $(1,32), p=.05)$ and hyperactive immature $(F=5.0(1,32), p<.05)$ scales were found to be significantly different between groups, but the interactions between status and time were non-significant.

\section{Discussion}

Overall, $38 \%$ of our fourth and sixth grade children were engaged in bullying behaviors. Their teachers identified approximately $20 \%$ of the children as BU; $15 \%$ as VI; and $4 \%$ as BV. Most of the research on bullying behavior has emanated from Europe with reported ranges of bullying behavior varying from 15-70\% [10]. A study in this country estimated that $30 \%$ of sixth to tenth-graders reported moderate or frequent involvement in bullying (13\% BU, 11\% VI, and $6 \%$ as BV [3]).

We found a number of interesting outcomes when comparing all children pre- and post-intervention. First, we showed that just being in school results in improvement on most of the behavioral and emotional measures across the school year. As reported by their teachers at the end of the school year, all children were significantly less conduct disordered, anxious/shy, restless/disorganized, and hyperactive/immature. In our study, BU were significantly more conduct disordered, restless/disorganized, antisocial and hyperactive compared to other children as well as those identified as VI. Our findings are resonant with others who have found that bullying behavior is a component of a generally more antisocial, conduct disordered, and aggressive behavior pattern [4]. The VI on the other hand were more likely to experience higher levels of anxiety and were significantly less conduct disordered than BU and BV. The BV was significantly more anxious than the BU and they were more hyperactive and immature than the VI. The BV comprises an interesting group. Generally, these children have been identified as having a proclivity for ADHD with a tendency to be provocative and intrusive with and subsequently being bullied by those whom they have provoked.

Comparing pre- and post-measures among all groups indicates that BU scored higher on conduct disorder, restless/disorganized, antisocial, hyperactive/immature, and hyperactivity index than the VI and NBV. The BV scored higher on conduct disorder than the NBV and the VI and they were higher than the NBV on hyperactive/ immature. The VI were higher on anxious/shy than the NBV. The $\mathrm{BU}$ and BV showed the greatest improvement over time on conduct disorder, restless/disorganized, antisocial, and hyperactive/ immature and hyperactivity index, indicating that they were the most responsive to the intervention. The BV and the VI showed a greater effect over time than the BU and the NBV for anxious/shy. By the end of the year, the BU and the BV had improved in all behavioral measures, except antisocial, and in contrast to other children they failed to improve in their level of anxiety. The VI improved on all measures except antisocial behaviors. In general, the changes in CRS scores for BU, BV, and VI were significantly greater over time than the difference that occurred for NBV, suggesting the improvements were independent of the passage-of-time effect.

A comparison of boy BU to girl BU revealed that the boys were more likely to score higher on the hyperactivity index. We found no significant differences on any scale of the CRS when comparing the 
boy VI to girl VI. A comparison of fourth grade to sixth grade BU indicated that fourth graders were more conduct disordered and antisocial. At the end of the school year, the sixth graders showed greater improvements in conduct disorder, anxious/shy, restless/ disorganized, and hyperactive/immature behaviors, suggesting that they were either more responsive to the intervention or a motivation-social learning effect. We found the fourth grade VI to be more conduct disordered, antisocial, and hyperactive immature than the sixth grade VI. The score for sixth grade VI improved significantly more than for the fourth graders for conduct disorder and restless-disorganized showing that they were also likely to be more responsive to the intervention.

\section{Limitations}

The findings of our research are limited by several methodological concerns. We did not perform any test-retest reliability pilot studies prior to the pre-intervention assessments; therefore our data may be limited in this capacity. Even though we conducted information sessions about bullying and other behaviors before pre- and post-intervention data collection, we cannot be entirely certain that the teachers were consistent in assessing their students across time. Also, teachers may have felt the need to bias their responses on the CRS in a way that did not implicate their students in any very severe manner. We did not collect crossinformant data, e.g., the students or parents, so we had no way of corroborating BU and/or VI classifications, and we also had no way of knowing if these behaviors occur outside the classroom. Finally, we only collected data on the fourth and sixth grades, so one should be cautious in generalizing our data to other grades, i.e., ages, of students.

\section{References}

1. Holmes SR, Brandenberg-Ayres SJ (1998) Bullying behavior in school: A predictor of later gang involvement. Journal of Gang Research 5(2):1-6.

2. Olweus D (1992) Bullying among school children: Intervention and prevention. In R.D. Peters, RJ McMahon, VI Quincey (Eds.) Aggression and violence through the life span, (315-342). Newbury Park, CA, USA.

3. Nansel TR, Overpeck M, Pilla RS, Ruan WJ, Simons-Morton B, et al. (2001) Bullying behavior among US youth. Journal of the American Medical Association 285(16): 2094-2100.

4. Olweus D (1997) Bully/victim problems in school: Facts and intervention. European Journal of Psychology of Education 12(4): 495-510.

5. Golvin G, Tobin T, Beard K, Hagen S, Sprague J (1998) The school bully: Assessing the problem. Developing interventions, and future research directions. Journal of Behavioral Education 8(3): 293-319.

6. Bonds M \& Stoker S (2000) Bully-proofing your school: A comprehensive approach for middle schools. Sopris West, Longmont, CO.

7. Olweus D (1997) Bully/victim problems in school: Knowledge base and an effective intervention program. The Irish Journal of Psychology 18(2): 170-190.

8. Olweus D (1991) Bully/victim problems among school children: Basic facts and effects of a school based intervention program. In D. Pepler \& K. Rubin (Eds.) The development and treatment of childhood aggression. Erlbaum, Hillsdale, New Jersey, USA .

9. Garrity C, Jens K, Porter W, Sager N, Camilli C (2000) Bully-proofing your school, A comprehensive approach for elementary schools. Sopris West, Longmont, CO.

10. King A, Wold B, Tudor-Smith, Harel Y, The Health of Youth: A Cross National Survey. Canada: WHO Regional Publications, European Series No. 69.

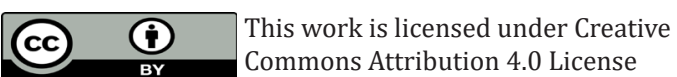

To Submit Your Article Click Here: Submit Article

DOI: 10.32474/PRJFGS.2018.01.000114

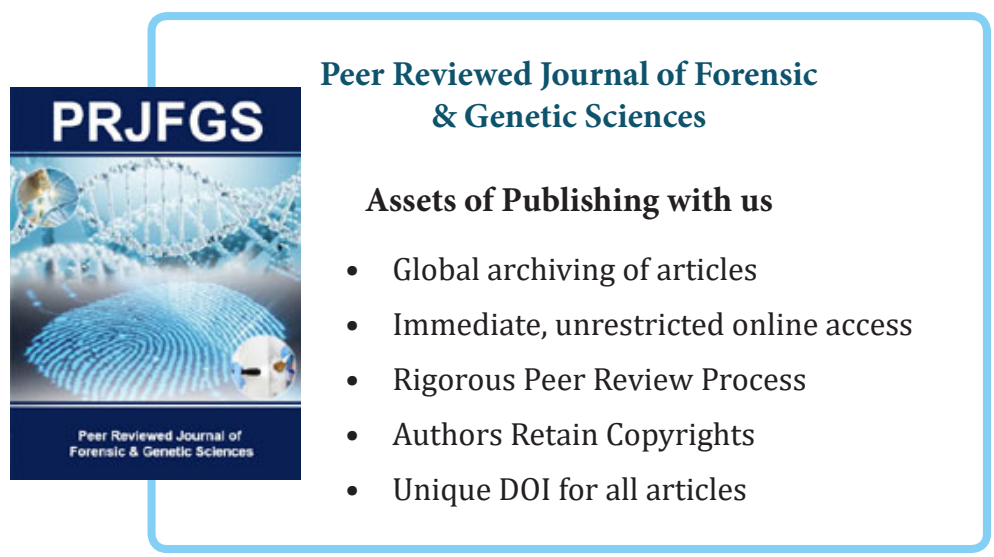

